\title{
Production of Human Parvovirus 4 VP2 Virus-Like Particles in Yeast and Their Evaluation as an Antigen for Detection of Virus-Specific Antibodies in Human Serum
}

\author{
Paulius Lukas Tamošiūnas ${ }^{a} \quad K^{2}$ arolis Simutis ${ }^{a} \quad$ Indrè Kodzè ${ }^{a} \quad$ Regina Firantiené $^{b}$ \\ Regina Ėmužyté $^{b}$ Rasa Petraitytè-Burneikiené ${ }^{\mathrm{a}} \quad$ Aurelija Žvirbliené ${ }^{\mathrm{a}}$ \\ Kęstutis Sasnauskas ${ }^{a}$ \\ ${ }^{a}$ Institute of Biotechnology, and ${ }^{b}$ Clinic of Children's Diseases, Faculty of Medicine, Vilnius University, Vilnius, Lithuania
}

\section{Key Words}

Human parvovirus 4 - Capsid protein - Virus-like particle

\begin{abstract}
Background: Human parvovirus 4 (PARV4) is a recently discovered member of the Parvoviridae family, which is not closely related to any previously discovered human parvoviruses. PARV4 has been isolated from the plasma of individuals with symptoms of acute viral infection; however, until recently PARV4 had not been associated with any disease, and its prevalence in the human population is yet to be established. Methods: The major capsid protein VP2 of PARV4 was generated in the yeast Saccharomyces cerevisiae and used for serological detection of virus-specific lgG and IgM in the sera of low-risk individuals. Results: One hundred and seventy serum specimens obtained from patients with acute respiratory diseases were tested for PARV4-specific lgG and IgM antibodies. Sixteen individuals (9.4\%) were diagnosed as seropositive, including $6 \mathrm{lgM}$ and $\lg G$ positive, $6 \mathrm{lgM}$ positive/lgG negative and $4 \mathrm{lgG}$ positive/lgM negative. Seven of the 16 seropositive individuals were between the ages of 3 and 11 with no evidence of parenteral exposure to PARV4 infection. Conclusion: Our data demonstrate that recombinant yeastderived VP2 protein, self-assembled to virus-like particles,
\end{abstract}

can represent a useful tool when studying the seroprevalence of PARV4 infection. The presence of PARV4-specific antibodies in a low-risk group may indicate the possibility of alternative routes of virus transmission.

Copyright $\odot 2013$ S. Karger AG, Basel

\section{Introduction}

Parvoviruses are small, nonenveloped viruses containing a single-stranded linear DNA genome of around $5 \mathrm{~kb}$. This genome contains two open reading frames which encode for nonstructural and capsid proteins [1]. Parvoviruses are widespread pathogens that cause a wide range of diseases in both humans and animals. Before the discovery of several novel human parvoviruses in 2005, only two members of the family Parvoviridae, parvovirus B19 and adenoassociated virus, were known to infect humans [2]. In 2005, human bocavirus, associated with respiratory diseases in children, was identified and characterized [3]. In the same year, human parvovirus 4 (PARV4) was identified in the plasma of an intravenous drug user with acute viral syndrome. This was achieved through the use of a sequenceindependent polymerase chain reaction (PCR) amplification method. PARV4 was found to possess $<30 \%$ of amino

\section{KARGER}

E-Mail karger@karger.com

www.karger.com/int
(C) 2013 S. Karger AG, Basel

0300-5526/13/0565-0271\$38.00/0
Paulius Lukas Tamosiunas

Institute of Biotechnology, Vilnius University

V. A. Graiciuno 8

LT-02241 Vilnius (Lithuania)

E-Mail paulius.tamosiunas@ bti.vu.lt 
acid sequence similarity to other parvoviruses, and it formed a distinct branch upon phylogenetic analysis [4].

The epidemiology and the clinical implication of PARV4 in the human population is still under evaluation. PARV4 DNA has been found to be a common contaminant of plasma pools and can be detected in $4-5 \%$ of plasma specimens by PCR [5]. The reported prevalence of PARV4 DNA in healthy individuals from different parts of the world varies from 0.1 to $24 \%$. Epidemiologic situations may differ greatly from country to country and warrant further study [6-11]. Viruses closely related to PARV4 were also identified in porcine and bovine serum samples [12].

Compared to other parvoviruses that are predominantly transmitted through respiratory or gastrointestinal routes, PARV4 infections show an unusual risk-group association. Initial studies have shown that the virus has been present in the blood of intravenous drug users and individuals positive for HCV or HIV, as well as people with hemophilia, patients on hemodialysis and lung transplant recipients $[5,6,13-16]$. The finding of viral DNA in tissues of intravenous drug users indicates that the virus can be transmitted by parenteral means, but whether this is the only route of virus transmission is still unknown [17].

Diagnostic test systems for parvovirus infection are based on the detection of either virus-specific antibodies or viral DNA. The long-lasting antibodies against parvoviruses are preferentially directed against conformational epitopes present in VP2 proteins $[18,19]$. This means that current diagnostic enzyme immunoassay (EIA) tests for parvoviruses rely on recombinant VP2-based virus-like particles (VLPs) as a specific antigen that is produced preferentially in baculovirus expression systems [20,21].

The formation of recombinant parvoviral capsid protein VLPs in yeast has been recently demonstrated [19, 22]. Yeast-derived B19 VLPs can resemble native virus or recombinant VP2-VLPs produced by baculovirus systems in respect of size, molecular weight and antigenicity. Regarding costs, yield and ease of handling, VLP production in yeast represents an alternative to the recombinant baculovirus expression system, which is so far the dominating source of VP2-VLPs of parvoviruses [19].

The aim of the current study was to investigate the possibilities of producing PARV4 VP2 as VLPs in yeast expression system and to evaluate the antigenic properties of yeast-derived VLPs for their use in PARV4 serology. In this paper, we describe the generation of recombinant PARV4 VP2 VLPs in yeast and demonstrate the utility of yeast-derived VLPs for detecting PARV4-specific IgM and IgG in human sera.

\section{Materials and Methods}

\section{Serum Samples}

Serum samples from patients with acute respiratory disease were obtained from Vilnius University, Faculty of Medicine, Clinic of Children's Diseases (Lithuania). Serum samples were investigated for PARV4-specific antibodies by an in-house developed EIA and for the presence of virus-specific DNA by PCR, as described in Fryer et al. [5]. The clinical diagnosis of respiratory tract infections was confirmed at the sera collection day by the presence of typical acute respiratory viral infection symptoms, including sneezing, nasal obstruction and discharge, sore throat, cough and moderate fever. Collection of specimens and clinical data was approved by the Lithuanian Bioethics Committee (No. 53, 2008-09-03).

Cloning of PARV4 VP1 and VP2 Encoding Sequences into

Yeast Vectors and Purification of VLPs from Yeast

All DNA manipulations were performed according to standard procedures [23]. Enzymes, molecular mass standards and kits for DNA manipulations were purchased from Fermentas/ Thermo Fisher Scientific (Vilnius, Lithuania). PARV4 VP1 gene was chemically synthesized by Genscript (Piscataway, N.J., USA) according to the published sequence GenBank accession No. EU546204 [24].

The VP2 gene was amplified by PCR from VP1 sequence by using specific primers:

GC-3'

P4_FW2 5'-GCACCTAGGACAATGTAGTAGTTGGCAAT-

P4_RV 5'-CGACCTAGGTTATAGCAAATGAGAATAATTTCGCG-3'

ATG and termination codons are indicated in bold and cloning site for restriction endonuclease XmaJ are underlined. The structure of both genes was confirmed by sequencing. For the expression of both PARV4 VP1 and VP2 proteins, the yeast expression vector $\mathrm{PFX} 7$ containing inserted VP1 or VP2 genes under control of yeast GAL1-10 promoter was used. Cultivation of transformed yeast cells as well as the expression and purification of recombinant proteins were performed as previously described $[25,26]$. Cultivated yeast cells were disrupted briefly through vortexing with glass beads, and the clarified lysate was subjected to centrifugation through $30 \%$ sucrose cushion. Precipitates were suspended and centrifuged for $40 \mathrm{~h}$ in a cesium chloride gradient.

\section{Strains, Media, Yeast Transformation and Cultivation}

Recombinant constructs containing PARV4 VP1 and VP2 sequences were screened in Escherichia coli $\mathrm{DH} 5 \mathrm{aF}^{\prime}$ cells. Saccharomyces cerevisiae AH22 MATa (leu2 his4 pep4) were used for the expression of PARV4 VP2 protein. Selection of yeast transformants resistant to formaldehyde was carried out on the YEPD (1\% yeast extract, $2 \%$ peptone, $2 \%$ dextrose, Difco, Sparks, Md., USA) agar supplemented with $5 \mathrm{mM}$ formaldehyde as described previously [25]. S. cerevisiae transformants were grown in YEPD medium supplemented with $5 \mathrm{mM}$ formaldehyde or in YEPG induction medium ( $1 \%$ yeast extract, $2 \%$ peptone, $2 \%$ galactose, Difco).

\section{Electron Microscopy}

After purification by $\mathrm{CsCl}$ ultracentrifugation, suspension of the recombinant PARV4 VP2 protein was placed on 400-mesh carbon-coated copper grids (Agar Scientific, Stansted, UK). The 
protein samples were stained with $2 \%$ aqueous uranyl acetate solution (Reachim, Moscow, Russia) and examined with a Morgagni-268 electron microscope (FEI, Eindhoven, the Netherlands).

SDS-Polyacrylamide Gel Electrophoresis and Immunoblotting Analysis

The protein samples were boiled in a reducing sample buffer and separated in a SDS-Tris-glycine buffer through polyacrylamide gel electrophoresis (PAGE). Proteins were visualized by staining with Coomassie Brilliant blue (Sigma-Aldrich Co., St. Louis, Mo., USA). For immunoblotting, purified proteins were electro-transferred to Immobilon P membrane (Millipore, Bedford, Mass., USA), as described in Sambrook and Russell [23]. The membranes were blocked with blocking buffer ( $1 \times$ Roti-Block, Carl Roth $\mathrm{GmbH}$ and Co, Karlsruhe, Germany) for $2 \mathrm{~h}$ with shaking. Then, the blocking solution was removed, and the membranes were incubated with human sera diluted 1:200. Horseradish peroxidase-conjugated rabbit anti-human IgG (DakoCytomation, Glostrup, Denmark) and goat anti-human IgM (ThermoFisher, Rockford, Ill., USA) secondary antibodies were used for the detection of human IgG and human IgM, respectively. The blots were stained with 3,3',5,5'-tetramethylbenzidine (TMB) ready-to-use chromogenic substrate (Clinical Science Products Inc., Mansfield, Mass., USA).

\section{Enzyme Immunoassay}

Ninety-six-well EIA plates (Nerbe Plus GmbH, Winsen/Luhe, Germany) were coated with $200 \mathrm{ng}$ per well of recombinant PARV4 VP2 protein in $100 \mu \mathrm{l}$ of $0.05 \mathrm{M}$ carbonate-bicarbonate coating buffer ( $\mathrm{pH}$ 9.6) and incubated overnight at $4^{\circ} \mathrm{C}$. Plates were washed four times with PBST [phosphate-buffered saline with $0.05 \%(\mathrm{v} / \mathrm{v})$ Tween 20, (BIO-RAD, Richmond, Calif., USA)] and then blocked by the addition of $300 \mu$ of blocking buffer per well ( $1 \times$ Roti-Block, Carl Roth $\mathrm{GmbH}$ and $\mathrm{Co}$ ) and incubation at room temperature for $1 \mathrm{~h}$ with shaking. After blocking, the plates were washed four times with PBST and 100- $\mu$ l aliquots of serum specimens diluted 1:200 in PBST buffer with $1 \%$ BSA were added to the wells. Plates were incubated for $1 \mathrm{~h}$ at $37^{\circ} \mathrm{C}$ with shaking and washed four times with PBST. 100- $\mu$ laliquots of either rabbit anti-human IgG (DakoCytomation) or goat anti-human IgM (ThermoFisher) conjugated to horseradish peroxidase, diluted 1:16,000 (v/v) in blocking buffer, were added to each well, and the plates were incubated for $1 \mathrm{~h}$ at $37^{\circ} \mathrm{C}$ with shaking. After washing four times with PBST, $100 \mu \mathrm{l}$ of TMB substrate (Clinical Science Products Inc.) was added to each well, and the enzyme reaction was stopped with an equal volume of $1 \mathrm{M} \mathrm{H}_{2} \mathrm{SO}_{4}$ following a 5-min incubation at room temperature. The optical density (OD) at $450 \mathrm{~nm}$ was determined for each sample using an EIA plate reader (Multiskan EX, Franklin, Mass., USA). Wells with an absorbed BSA $(n=72)$ or yeast-produced recombinant Tioman virus nucleocapsid protein $(n=72)$ were used as negative controls with the representative sera.

\section{Mass Spectrometric Analysis of Recombinant Proteins}

Mass spectrometric (MS) analysis of recombinant proteins was carried out according to Hellman et al. [27]. Proteins were identified by matrix-assisted laser desorption/ionization (MALDI) mass spectrometry using a 4,800 MALDI TOF/TOF mass spectrometer (AB/Sciex, Concord, Ont., Canada). Peptide mass spectra were acquired in reflector-positive ion mode with an $\mathrm{m} / \mathrm{z}$ range of 800 4,000 Da. Four hundred laser shots were summarized for each sample with a mass accuracy of $\pm 50 \mathrm{ppm}$. MS/MS spectra for dom-

PARV4 VP2 Virus-Like Particles for

Detection of Virus-Specific Antibodies inating peptides were acquired in positive mode with the ion collision energy set to $1 \mathrm{keV}$. Five hundred laser shots were accumulated for each spectrum with a mass accuracy of $\pm 0.1 \mathrm{Da}$. The proteins were identified in the TrEMBL database (3-23-10 release) using the Mascot algorithm.

\section{Results}

\section{Synthesis of PARV4 VP1 and VP2 Proteins in Yeast}

Expression efficiency of recombinant PARV4 VP1 and VP2 proteins in yeast was analyzed by electrophoresis. SDS-PAGE analysis of crude lysates of S. cerevisiae harboring $\mathrm{pFX}-\mathrm{VP} 1$ and $\mathrm{pFX}-\mathrm{VP} 2$ expression vectors revealed the presence of an additional protein band after induction with galactose. This band was approximately $105 \mathrm{kDa}$ in the lysates of yeast transformed with pFX-VP1 (fig. 1a, lane 1) and $61.5 \mathrm{kDa}$ in those transformed with pFX-VP2 (fig. 1b, lane 2). No additional band of the corresponding molecular size was observed in crude lysates of $S$. cerevisiae harboring pFX7 vector (fig. 1a, lane 2 , and fig. $1 \mathrm{~b}$, lane 1). After centrifugation of lysates through $30 \%$ sucrose cushion, the pellets harboring recombinant proteins were subjected to $\mathrm{CsCl}$ gradient centrifugation. $\mathrm{CsCl}$ gradients revealed recombinant proteins in fractions with buoyant density of $1.28-1.30 \mathrm{~g} / \mathrm{ml}$.

The expression level of PARV4 VP1 protein in transformed yeast was very low (fig. 1a, lane 1) and its purification through sucrose and $\mathrm{CsCl}$ gradients was not successful (data not shown). This suggested that VP1 protein of PARV4 produced in yeast either does not form VLPs or its self-assembly to VLPs is nonefficient, thus only recombinant PARV4 VP2 protein was used for further studies.

The SDS-PAGE analysis of the CsCl-purified VP2 protein revealed a band of $61.5 \mathrm{kDa}$ (fig. $1 \mathrm{~b}$, lane 3 ) with molecular mass corresponding to that predicted from gene sequences of PARV4 VP2 and that observed in crude lysates of pFX-VP2-transformed yeast (fig. 1b, lane 2). In order to confirm the sequence identity of the full-length recombinant PARV4 VP2 protein, MS analysis of purified recombinant protein was performed (data not shown).

\section{Electron Microscopy Analysis}

Formation of VLPs by PARV4 VP2 protein was confirmed by negative staining electron microscopy. Typical icosahedral structures of parvoviruses with a diameter of approximately 25-28 nM were observed indicating that PARV4 VP2 had self-assembled to VLPs (fig. 2). 
Fig. 1. PARV4 VP1 and VP2 synthesis in yeast. a SDS-PAGE analysis of yeast lysates. Additional band of approximately $105 \mathrm{kDa}$ in S. cerevisiae [pFX-VP1] lysate (lane 1) is indicated with an arrow. Lane 2: S. cerevisiae [pFX7] lysate. $\mathrm{M}=$ PageRuler Prestained Protein Ladder (Fermentas/Thermo Fisher Scientific). b SDS-PAGE analysis of yeast lysates and expressed PARV4 VP2 protein after ultracentrifugation in $\mathrm{CsCl} .5 \mu \mathrm{g}$ of purified VP2 protein (lane 3 ) and $20 \mu \mathrm{g}$ of yeast lysates (lanes 1 and 2) were separated in a $12 \%$ SDS-PAGE and stained with Coomassie brilliant blue. $\mathrm{M}=$ PageRuler Prestained Protein Ladder (Fermentas/Thermo Fisher Scientific). Lane 1: S. cerevisiae [pFX7] lysate; Lane 2: S. cerevisiae [pFX-VP2] lysate; Lane 3: CsCl purified PARV4 VP2.

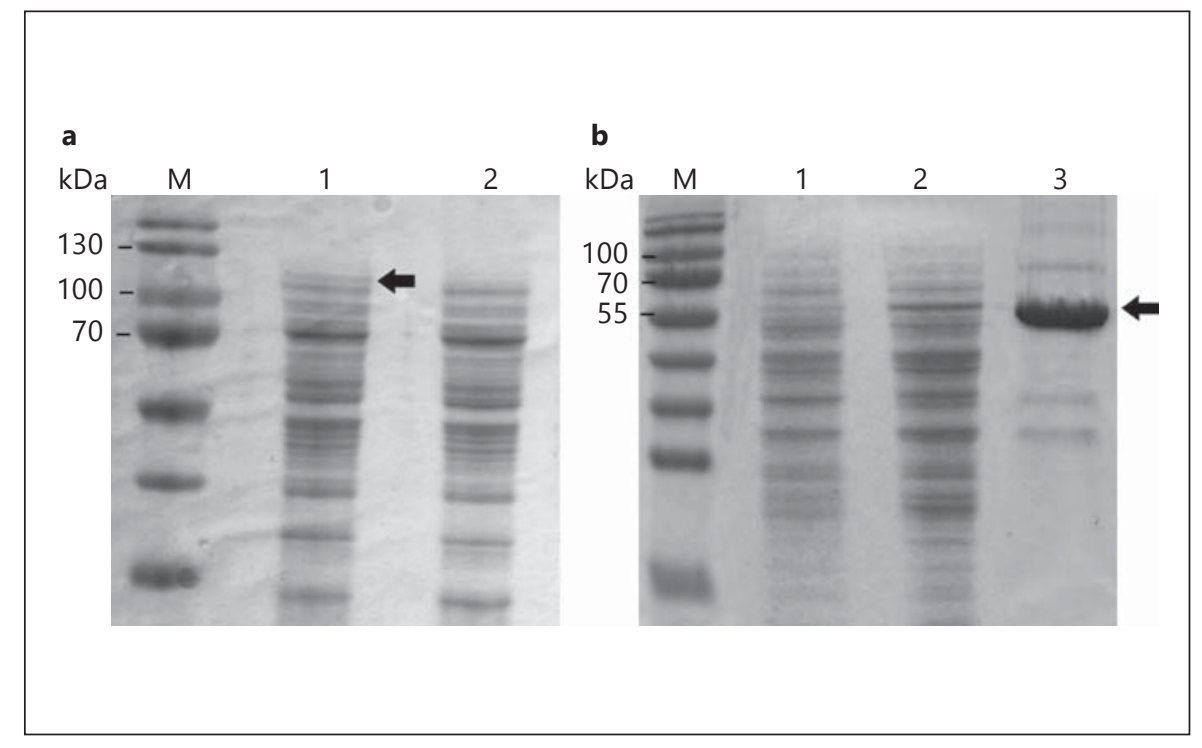

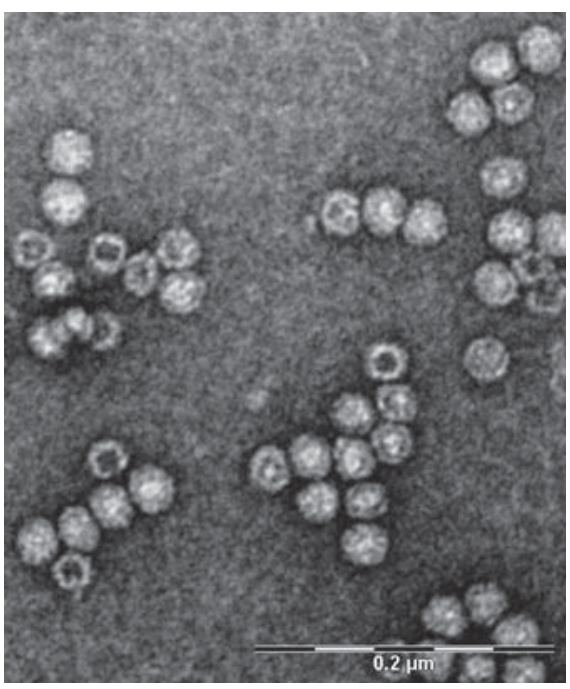

Fig. 2. Electron micrograph of $\mathrm{CsCl}$-purified PARV4 VP2 VLPs. Scale bar $=200 \mathrm{nM}$.

Yield and Stability of Recombinant PARV4 VP2 VLPS

In several preparative procedures, the yield of purified recombinant PARV4 VP2 protein was found to be 6-7 $\mathrm{mg} / \mathrm{l}$ of induced yeast culture (data not shown). After $\mathrm{CsCl}$ gradient purification, the protein was dialyzed against PBS containing $10 \mathrm{~mm}$ EDTA and stored at $-20^{\circ} \mathrm{C}$ in PBS containing $10 \mathrm{mM}$ EDTA and $40 \%$ glycerol. Treatment with $25 \mathrm{mM}$ EDTA or $10 \mathrm{~mm}$ EGTA did not cause the dissociation of recombinant VLPs indicating that the assembled structures do not require divalent ions (data not shown). Thus, the yeast system employed in this study has been shown to be suitable for efficient expression of PARV4 VP2 protein. Moreover, PARV4 VP2 protein produced in S. cerevisiae had the capacity to form VLPs in the absence of VP1 protein. Yeast-derived VP2 VLPs resembled native virus regarding both size and morphology.

The Reactivity of Recombinant PARV4 VP2 VLPs with Serum Antibodies from Low-Risk Group Individuals

Recombinant PARV4 VP2 VLPs were employed to develop EIA tests for the detection of PARV4-specific IgM and IgG antibodies in human serum. Since commercial serologic test systems for PARV4 infection were not available, it was not possible to define anti-PARV4 positive and negative sera. The PCR analysis of serum specimens was unable to confirm PARV4 infection because PARV4 DNA was not detectable in the sera (data not shown). This meant that the cutoff values for the serologic assay were set conservatively as the mean absorbance +3 standard deviations (SD) and used to assign samples as anti-PARV4 positive or negative [21]. The cutoff values for the positive sera were determined using the mean OD value of the negative controls $(\mathrm{n}=144)$ plus $3 \mathrm{SD}($ mean $+3 \mathrm{SD})$. Sera with an OD between mean $+2 \mathrm{SD}$ and mean $+3 \mathrm{SD}$ were regarded as equivocal [28]. In this study, the cutoff OD values for positive sera were 0.411 and 0.597 for IgG and IgM, respectively. Equivocal sera for IgG had OD values between 0.290 and 0.411 , whilst for IgM the ODs were between 0.415 and 0.597 .

Analysis of the 170 serum specimens isolated from patients with acute respiratory disease (table 1 ) revealed that $5.8 \%(n=10)$ sera were $\operatorname{IgG}$ positive and $7 \%(\mathrm{n}=12)$ sera were IgM positive. PARV4 seroprevalence may be 
Fig. 3. Immunoblot analysis of antiPARV4-positive sera. Left: stained SDSPAGE gel of purified recombinant PARV4 VP2 protein. $\mathrm{M}=$ PageRuler Prestained Protein Marker (Fermentas/Thermo Fisher Scientific). Right: Immunoblot strips of EIA-positive sera are indicated by the identification number and secondary antibody used. Strips with serum No. 138 were provided to act as a negative control. Negative control antigen Tioman NC $(\sim 58 \mathrm{kDa})$ showed no reactivity in Western blotting when used with positive serum No. 20 (arrows indicate the position of blotted antigen).

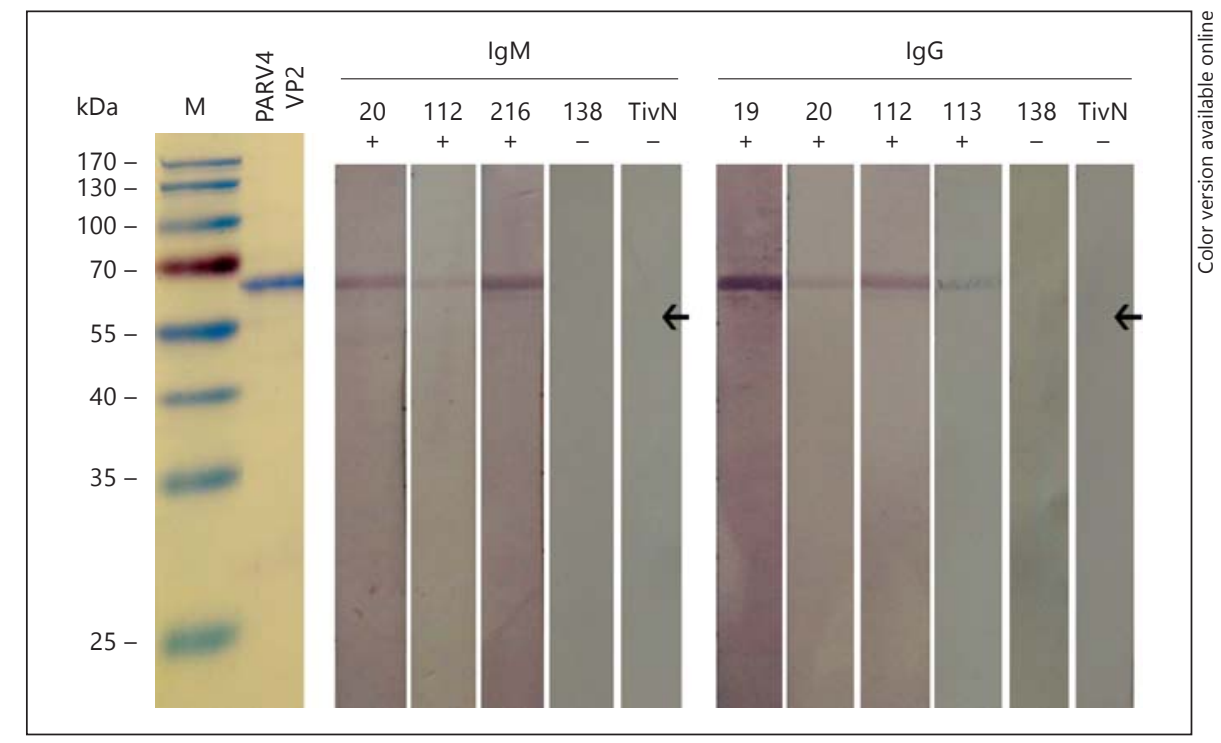

grouped into three groups: 4 patients with serological evidence of past infection (IgM-, IgG+), 6 patients with possible current infection (IgM+, IgG- or equivocal), and 6 patients with ongoing or recent infection $(\operatorname{IgM}+, \operatorname{IgG}+)$. Among 16 seropositive individuals, 7 were children between the ages of 3 and 11. Results of the VP2-based EIA test are presented in table 2.

\section{Immunoblot Analysis of Anti-PARV-Positive Serum \\ Specimens}

In order to confirm the results obtained by EIA, an immunoblot analysis of all PARV4 VP2-specific IgM- and IgG-positive sera was carried out. Ten PARV4 IgG-positive and 12 PARV4 IgM-positive serum specimens were analyzed.

Through immunoblotting, 4 of the 10 analyzed EIA IgG-positive serum specimens showed a specific positive IgG reactivity with PARV4 VP2 protein, while 3 of the 12 analyzed EIA IgM-positive serum specimens showed VP2-specific positive IgM reactivity (fig. 3). Two of all the analyzed sera were positive for both IgG and IgM antibodies specific to PARV4 VP2 protein. The results of both EIA and immunoblot analysis of the human serum specimens are summarized in table 2.

\section{Discussion}

When viral surface proteins are expressed in a eukaryotic host with no other viral gene products present, many of them have the intrinsic capacity to self-assemble into
Table 1. Demographic characteristics of study subjects

\begin{tabular}{lcll}
\hline & $\begin{array}{l}\text { Number of } \\
\text { samples }\end{array}$ & $\begin{array}{l}\text { Mean age (range), } \\
\text { years }\end{array}$ & $\begin{array}{l}\text { Number of EIA- } \\
\text { positive samples }\end{array}$ \\
\hline $\begin{array}{l}\text { Female } \\
\text { Male }\end{array}$ & 78 & $21.1(0.5-63)$ & 2 \\
\hline Total & 170 & $20.0(0.5-60)$ & 14 \\
\hline
\end{tabular}

Table 2. PARV4 enzyme immunoassay and immunoblot results

\begin{tabular}{|c|c|c|c|c|c|c|}
\hline \multirow{2}{*}{$\begin{array}{l}\text { Serum } \\
\text { No. }\end{array}$} & \multicolumn{2}{|c|}{ EIA, OD ${ }^{a}$} & \multicolumn{2}{|c|}{ Immunoblot } & \multirow{2}{*}{$\begin{array}{l}\text { Age, } \\
\text { years }\end{array}$} & \multirow[t]{2}{*}{ Sex } \\
\hline & $\operatorname{Ig} M$ & IgG & $\operatorname{Ig} M$ & IgG & & \\
\hline 19 & 0.618 & 0.654 & & + & 25 & $\mathrm{M}$ \\
\hline 20 & 1.014 & 0.687 & + & + & 46 & $\mathrm{M}$ \\
\hline 23 & 0.619 & & & & 47 & $\mathrm{M}$ \\
\hline 31 & & 0.494 & & & 23 & M \\
\hline 43 & 0.786 & & & & 26 & $\mathrm{M}$ \\
\hline 84 & & 0.445 & & & 15 & $\mathrm{M}$ \\
\hline 85 & & 0.455 & & & 16 & $\mathrm{M}$ \\
\hline 86 & 0.603 & & & & 5 & $\mathrm{~F}$ \\
\hline 112 & 1.213 & 0.728 & + & + & 6 & $\mathrm{M}$ \\
\hline 113 & 0.636 & 0.453 & & + & 10 & $\mathrm{M}$ \\
\hline 116 & 0.803 & & & & 10 & M \\
\hline 117 & 0.742 & & & & 14 & $\mathrm{M}$ \\
\hline 127 & 0.628 & & & & 3 & $\mathrm{M}$ \\
\hline 138 & 0.639 & 0.435 & & & 9 & $\mathrm{~F}$ \\
\hline 209 & & 0.419 & & & 19 & $\mathrm{M}$ \\
\hline 216 & 0.790 & 0.498 & + & & 11 & $\mathrm{M}$ \\
\hline
\end{tabular}

a Only values that are interpreted as seropositive are shown in the table. 
VLPs $[29,30]$. VLPs are an excellent tool for developing diagnostics and vaccines. In this study, we have demonstrated that the yeast $S$. cerevisiae is a suitable host for the production of recombinant PARV4 VP2 protein as VLPs. Yeast-derived VP2 VLPs may provide a useful alternative to the baculovirus expression system which was described previously [19].

We have used yeast-derived PARV4 VP2 VLPs for the detection of virus-specific antibodies in low-risk groups of individuals including children. Serum specimens were obtained from patients with confirmed respiratory tract infections.

VP2-based EIA analysis of 170 serum specimens for anti-PARV4 revealed 12 IgM-positive and 10 IgG-positive sera. Six of these serum specimens showed a positivity for both IgG and IgM antibodies, whereas 6 were IgM positive/IgG negative and 4 were IgG positive/IgM negative. The reactivity of serum antibodies with yeast-derived VP2 VLPs confirms their antigenic similarities with native PARV4.

Immunoblot analysis of the same sera confirmed the presence of PARV4 VP2-specific IgM in 4 serum specimens and the presence of PARV4 VP2-specific IgG in 3 serum specimens. Two of the immunoblot-positive sera contained both IgM and IgG antibodies specific to PARV4 VP2 protein. The results obtained by EIA and Western blotting might be different due to the differences in antigen structures. This is because in EIA native antigens were immobilized onto microtiter plates, whereas in the Western blot assays antigens that had been denatured with SDS were used. As the majority of serum antibodies induced by a natural PARV4 infection target conformational epitopes [18, 19], only a part of serum antibodies would recognize the SDS-denatured viral antigens. This would result in a reduction in the sensitivity of the Western blotting assay in comparison to EIA. Our study is the first attempt to evaluate the seropositivity for PARV4 in low-risk Lithuanian patients. Previous studies indicated that the epidemiologic situation with regard to PARV4 infections may differ greatly from country to country [6-11]. These dissimilarities could be related to geographical or social differences [20]; however, no major pattern of virus spread in a low-risk cohort has been characterized. We have demonstrated that the seroprevalence of PARV4-specific IgG and IgM antibodies (5.8 and $7 \%$, respectively) in a group of patients with acute respiratory disease was higher when compared to the results of low-risk patient cohorts obtained from other countries $[7,20]$. It is important to note that among 16 seropositive individuals, 7 were children between the ages of 3 and 11 . These results raise doubts in the current theory that PARV4 virus uses a parenteral transmission path, which was postulated after investigations of intravenous drug users and HIV-infected individuals [21]. In our study, all analyzed patients were low-risk individuals for PARV4 infection as they had no medical records of parenteral exposure. The absence of parenteral risks raises the possibility of alternative routes of transmission that might affect the general nonparenterally exposed population. This would explain why more cases of PARV4-infected children have been recently reported in Ghana. Proving nonparenteral transmission would suggest more widespread distribution of PARV4 in humans than previously expected and occurrence of virus in additional population subsets [31].

In summary, our study demonstrates that recombinant yeast-expressed PARV4 VP2 VLPs resemble native virus with regard to antigenicity and morphology. The results of the analysis of human serum specimens by VP2based immunoassays confirmed that yeast-derived VLPs represent a useful diagnostic tool for studying the seroprevalence of PARV4 infection.

\section{Acknowledgement}

This study was supported by the Lithuanian Science Council Grant No. MIP-060/2011. The authors thank Ms. L. Weir (University of Edinburgh, UK) for editing the language of the manuscript.

\section{References}

1 Tattersall P, Bergoin M, Bloom ME, Brown KE, Linden RM, Muzyczka N, Parrish CR, Tijssen P: Family Parvoviridae; in Fauquet CM, Mayo MA, Maniloff J, Desselberger U, Ball LA (eds): Virus Taxonomy: Eighth Report of the International Committee on Taxonomy of Viruses. San Diego, Elsevier Academic Press, 2005, pp 353-369.

2 Berns K, Parish CR: Parvovirus; in Knipes DM, Howley PM, Griffin DE, Lamb RA, Mar- tin MA, Roizman B, et al (eds): Fields Virology, ed 4. Philadelphia, Wolkers Kluwer/Lippincott, Williams and Wilkins, 2007.

-3 Allander T, Tammi MT, Eriksson M, Bjerkner A, Tiveljung-Lindell A, Andersson B: Cloning of a human parvovirus by molecular screening of respiratory tract samples. PNAS 2005; 102:12891-12896.

4 Jones MS, Kapoor A, Lukashov VV, Simmonds P, Hecht F, Delwart E: New DNA vi- ruses identified in patients with acute viral infection syndrome. J Virol 2005;79:8230-8236.

5 Fryer JF, Kapoor A, Minor PD, Delwart E, Baylis SA: Novel parvovirus and related variant in human plasma. Emerg Infect Dis 2006; 12:151-154.

6 Vallerini D, Barozzi P, Quadrelli C, Bosco R, Potenza L, Riva G, et al: Parvoviruses in blood donors and transplant patients, Italy. Emerg Infect Dis 2008;14:185-186. 
7 Tolfvenstam T, Norbeck O, Ohrmalm L: No evidence of presence of parvovirus 4 in a Swedish cohort of severely immunocompromised children and adults. PLoS One 2012; 7:e46430.

-8 Fryer JF, Delwart E, Bernardin F, Tuke PW, Lukashov VV, Baylis SA: Analysis of two human parvovirus PARV4 genotypes identified in human plasma for fractionation. J Gen Virol 2007;88:2162-2167.

$\checkmark 9$ Servant-Delmas A, Laperche S, Mercier M, Elghouzzi M-H, Lionnet F, Stankovic K, et al: Human parvovirus 4 in recipients of cellular products and in blood donors: epidemiologic similarity with B19 parvovirus. Transfusion 2009;49:1771-1773.

-10 Botto S, Bergallo M, Sidoti F, Terlizzi ME, Astegiano S, Ponti R, et al: Detection of PARV4, genotypes 1 and 2, in healthy and pathological clinical specimens. New Microbiol 2009;32: 189-192.

-11 Touinssi M, Brisbarre N, Picard C, Frassati C, Dussol B, Uch R, et al: Parvovirus 4 in blood donors, France. Emerging Infect Dis 2010;16: 165-166.

-12 Lau SKP, Woo PCY, Tse H, Fu CTY, Au W-K, Chen $\mathrm{X}-\mathrm{C}$, et al: Identification of novel porcine and bovine parvoviruses closely related to human parvovirus 4. J Gen Virol 2008;89: 1840-1848.

$>13$ Biagini P, Dussol B, Touinssi M, Brunet P, Picard C, Moal V, et al: Human Parvovirus 4 in kidney transplant patients, France. Emerg Infect Dis 2008;14:1811-1812.

-14 Fryer JF, Hubbard AR, Baylis SA: Human parvovirus PARV4 in clotting factor VIII concentrates. Vox Sang 2007;93:341-347.

15 Lurcharchaiwong W, Chieochansin T, Payungporn S, Theamboonlers A, Poovorawan Y: Parvovirus 4 (PARV4) in serum of intravenous drug users and blood donors. Infection 2008;36:488-491.
16 Touinssi M, Reynaud-Gaubert M, Gomez C, Thomas P, Dussol B, Berland Y, et al: Parvovirus 4 in French in-patients: a study of hemodialysis and lung transplant cohorts. J Med Virol 2011;83:717-720.

17 Brown KE: The expanding range of parvoviruses which infect humans. Rev Med Virol 2010;20:231-244

18 Söderlund M, Brown CS, Spaan WJ, Hedman L, Hedman K: Epitope type-specific IgG responses to capsid proteins VP1 and VP2 of human parvovirus B19. J Infect Dis 1995;172: 1431-1436.

19 Lowin T, Raab U, Schroeder J, Franssila R, Modrow S: Parvovirus B19 VP2-proteins produced in Saccharomyces cerevisiae: comparison with VP2-particles produced by baculovirus-derived vectors. J Vet Med B Infect Dis Vet Public Health 2005;52:348-352.

20 Lahtinen A, Kivelä P, Hedman L, Kumar A, Kantele A, Lappalainen M, et al: Serodiagnosis of primary infections with human parvovirus 4, Finland. Emerg Infect Dis 2011;17: 79-82.

21 Sharp CP, Lail A, Donfield S, Simmons R, Leen C, Klenerman P, et al: High frequencies of exposure to the novel human parvovirus PARV4 in hemophiliacs and injection drug users, as detected by a serological assay for PARV4 antibodies. J Infect Dis 2009;200. 1119-1125.

22 Backovic A, Cervelli T, Salvetti A, Zentilin L, Giacca M, Galli A: Capsid protein expression and adeno-associated virus like particles assembly in Saccharomyces cerevisiae. Microb Cell Fact 2012;11:124.

23 Sambrook J, Russell DW: Molecular Cloning: A Laboratory Manual, ed 3. Cold Spring Harbor Laboratory Press, Cold Spring Harbor, 2001.
24 Schneider B, Fryer JF, Oldenburg J, Brackmann $\mathrm{H}-\mathrm{H}$, Baylis SA, Eis-Hübinger AM: Frequency of contamination of coagulation factor concentrates with novel human parvovirus PARV4. Haemophilia 2008;14:978-986.

25 Samuel D, Sasnauskas K, Jin L, Beard S, Zvirbliene A, Gedvilaite A, et al: High level expression of recombinant mumps nucleoprotein in Saccharomyces cerevisiae and its evaluation in mumps IgM serology. J Med Virol 2002;66: 123-130.

26 Samuel D, Sasnauskas K, Jin L, Gedvilaite A, Slibinskas R, Beard S, et al: Development of a measles specific IgM ELISA for use with serum and oral fluid samples using recombinant measles nucleoprotein produced in Saccharomyces cerevisiae. J Clin Virol 2003;28: 121-129.

$\checkmark 27$ Hellman U, Wernstedt C, Gonez J, Heldin $\mathrm{CH}$ : Improvement of an 'in-gel' digestion procedure for the micropreparation of internal protein fragments for amino acid sequencing. Anal Biochem 1995;224:451-524.

28 Jacobson RH: Validation of serological assays for diagnosis of infectious diseases. Rev - Off Int Epizoot 1998;17:469-526.

29 Pumpens P, Ulrich RG, Sasnauskas K, Kazaks A, Ose V, Grens E: Construction of novel vaccines on the basis of the virus-like particles: hepatitis B virus proteins as vaccine carriers; in Khudyakov Y (ed): Medicinal Protein Engineering. Boca Raton, CRC Press, 2009, pp 205-248.

30 Pushko P, Pumpens P, Grens E: Development of virus-like particle technology from small highly symmetric to large complex virus-like particle structures. Intervirology 2013;56: 141-165.

31 Panning M, Kobbe R, Vollbach S, Drexler JF, Adjei S, Adjei O, et al: Novel human parvovirus 4 genotype 3 in infants, Ghana. Emerg Infect Dis 2010;16:1143-1146. 